\title{
Surveying the Damage: Academic Library Serial Cancellations 1987-88 through 1989-90
}

\section{Tina E. Chrzastowski and Karen A. Schmidt}

\begin{abstract}
A longitudinal study of serial cancellations was conducted by analyzing the cancellation lists between 1987 and 1990 from five midwestern libraries of the Association of Research Libraries. The study was designed to test the primary hypothesis that large academic libraries, faced with the same negative impacts on their budgets, are cancelling the same or similar types of serials. This hypothesis was disproved. Results of the study showed that, of 6,503 cancelled titles, only 281 (4 percent) were cancelled at more than one library, resulting in 6,222 (96 percent) unique title cancellations within this survey. Results also provide an overall profile of the at-risk journal. An additional survey of collection development officers gives insight into the cancellation decision-making process. The impact on serial collections in research libraries is also explored.
\end{abstract}

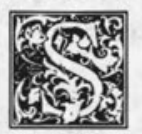

erial cancellations have become a regular and anticipated event in many academic libraries. Reports and studies of shrinking collections have appeared in the literature and have been summarized by Ann Okerson and the Association of Research Libraries (ARL), among others. ${ }^{1}$ Most of these studies have focused on serial prices and publisher practices and have shown how purchasing power for libraries has diminished or how prices have escalated over time. ${ }^{2}$ Data from these studies demonstrate the effects of serial cost increases on specific libraries or specialized collections within libraries and point to problems with specific publishers. These studies do not look at cancellations in a collective way or seek to interpret the effect such wide-ranging cancellations may be having on our combined serial collection profiles.

The depth and breadth of the serial cancellations wave that began in 1987 have reportedly devastated some libraries throughout the United States and seem likely to change the complexion of research library collections in the future. ${ }^{3}$ Because of the persistence of conditions leading to cancellations, librarians need to look collectively at library serial cancellations on a regional or national level. The interconnections that libraries of all types and sizes have made to facilitate resource sharing, answer reference questions, and enhance broad-based

Tina E. Chrzastowski is Chemistry Librarian and Karen A. Schmidt is Acquisitions Librarian at the University of Illinois at Urbana-Champaign, Urbana, IL 61801. The authors wish to acknowledge the University of Illinois at Urbana-Champaign (UIUC) Library's Research and Publication Committee, which provided support for the completion of the research reported in this paper. The Committee on Institutional Cooperation and former UIUC University Librarian David Bishop provided additional financial support. Shu Pei, graduate assistant on this project, and Lisa German, UIUC Library Acquisitions and Binding, assisted with the project. 
access to published knowledge show that libraries are committed to relying upon one another. However, while libraries routinely discuss cooperative collection development issues, serial cancellations are often made without consultation with other libraries. Time constraints in meeting deadlines for serial credits with vendors and the delay in receiving target goals of actual deficit figures from campus administration units may account for this lack of consultation. If large-scale serial cancellations are being made throughout the country in many types of libraries, and if these cancellations are being made in relative isolation, it follows that the universe of serial collections is changing in dramatic and perhaps unfortunate ways.

If large-scale serial cancellations are being made throughout the country in many types of libraries, and if these cancellations are being made in relative isolation, it follows that the universe of serial collections is changing in dramatic and perhaps unfortunate ways.

What this change might be has not yet been investigated or clearly defined. There have not been any published reports on longitudinal studies comparing serial title cancellations in different libraries. The authors' study is designed to provide empirical information about which titles have been cancelled at certain libraries and to help define the characteristics of a cancelled serial (which, for the purposes here, includes periodicals and continuations). This study also suggests ways in which serial cancellation decisions could be managed for the benefit of libraries in general and provides conclusions about the overall vitality of serial collections in research libraries throughout the country.

\section{HYPOTHESES}

The study first postulated that, if libraries of similar age, size, and mission were faced with the same external pres- sures, such as inflationary prices and a recessionary economy, they would cancel the same serial titles or titles of the same nature. It was also theorized that low-use and high-cost titles would be cancelled, with the result that the libraries studied would eventually end up with similar collections of heavily used serials.

With this in mind, two hypotheses were developed. The first stated that there would be a large number of identical serial titles cancelled at more than one library. A large number was defined at the outset to be more than 30 percent of the final number of serials cancelled in the libraries studied. Serial overlap studies have found that the possible universe of title overlap in journal collections can range from as low as 24 percent to as high as 68 percent in collections of similar size, age, and subject specialties. ${ }^{4.5}$

Because information on the characteristics of the cancelled serial was also being collected, the second hypothesis described the profile of a cancelled serial title. It was predicted that a typical cancelled serial would be in a science call number range and be a high-cost title. For the purposes of this study, high cost was defined as over $\$ 200$ per year. In addition, because libraries are forced to focus on maintaining core, high-use serial collections, it was predicted that over 50 percent of serial cancellations would be in a foreign language and published outside the United States.

\section{POPULATION}

Five Association of Research Libraries (ARL) libraries were selected for this study. They all represent publicly funded universities from the Midwest, and they are all members of the Committee on Institutional Cooperation (CIC). The CIC is an academic consortium of twelve midwestern research universities. ${ }^{6}$ The five libraries included in the study are at Michigan State University, Ohio State University, the University of Illinois at Urbana-Champaign, the University of Iowa, and the University of Wisconsin at Madison. The libraries at these institutions have large, research-oriented collections, 
TABLE 1

TOTAL EXPENDITURES FOR SERIALS 1987-88-1989-90

FOR THE FIVE SAMPLE LIBRARIES (From ARL Statistics)

\begin{tabular}{lrrrc}
\hline & \multicolumn{1}{c}{$1987 / 88$} & \multicolumn{1}{c}{$1988 / 89$} & $1989 / 90$ & $\%$ Change \\
\hline Illinois & $\$ 3,058,629$ & $\$ 3,063,482$ & $\$ 3,250,755$ & +5.9 \\
Iowa & $2,049,249$ & $2,195,108$ & $2,263,864$ & +9.5 \\
Michigan State & $1,979,604$ & $2,130,162$ & $2,289,075$ & +13.5 \\
Ohio State & $3,136,210$ & $3,270,224$ & $3,390,294$ & +7.5 \\
Wisconsin & $2,855,167$ & $2,867,836$ & $3,148,530$ & +9.3 \\
\hline
\end{tabular}

TABLE 2

TOTAL NUMBER OF SERIALS RECEIVED 1987-88-1989-90

INCLUDING GIFTS, EXCHANGE AND PAID SUBSCRIPTIONS FOR THE FIVE SAMPLE LIBRARIES (From ARL Statistics)

\begin{tabular}{llllc}
\hline \hline & $1987 / 88$ & $1988 / 89$ & $1989 / 90$ & $\%$ Change \\
\hline Illinois & 92,530 & 94,445 & 92,077 & -0.5 \\
Iowa & 22,877 & 24,119 & 24,176 & +5.4 \\
Michigan State & 29,556 & 28,754 & 28,910 & -2.2 \\
Ohio State & 31,154 & 32,005 & 32,870 & +5.2 \\
Wisconsin & 50,913 & 48,085 & 49,553 & -2.7 \\
\hline
\end{tabular}

as well as established methods of cooperating on many library issues. For the issues raised in this study, the CIC libraries serve as a homogenous group from which generalizations about research libraries can be extrapolated.

CIC Library Collection Development Officers (CDOs) meet regularly to discuss shared concerns and collection-related subjects of mutual interest. Serial budgets and resulting serial cancellations have been important topics in recent years. For this study, data on serial cancellations were requested from all the CIC libraries. From this group, cancellation lists from five libraries were selected, for the fiscal years 1987-88 through 1989-90, based on the availability of complete data. This three-year time frame represented the most complete data that could be obtained, but it should be pointed out that libraries may not cancel titles in a synchronized fashion.

Printed lists of cancelled titles were supplied by the CDO of each library. These lists contained varying information, but all included serial titles cancelled at that institution from 1987-88 through 1989-90.
Table 1 shows serial expenditures at these libraries for 1987-88 through 198990. Each library's serial budget increased during the study, although the five libraries reported serial cancellations each year of the study. Serial expenditures at the five libraries increased an average of 9 percent over the three budget cycles.

Table 2 shows the number of serials held at each institution from 1987-88 through 1989-90. This includes paid subscriptions, gifts, and exchanges. The average number of serial titles received in the five libraries increased by 1 percent during this time, and in three out of five libraries the number of serial titles received decreased. Data on the number of serial titles purchased at each library were not available. Data from these tables show that serial budget monies for these five institutions from 1987-88 through 1989-90 purchased fewer serials and paid more for them. In addition, monograph budgets were reduced in ARL libraries overall during the late 1980 s to maintain serial subscriptions, according to ARL statistics. ${ }^{7}$ 


\section{METHODOLOGY}

A database was created using PC-File, with fields selected to address questions suggested by the hypotheses. Nine items of information for each title were included: title, country of publication, language, institution cancelling the title, year of cancellation, price of title in year cancelled, Library of Congress call number, an indication if the title was received as a gift, and (if reported) if the title was a duplicate at that location. No consistent data on publishers of cancelled titles were available. Ohio State University reported that all of its cancelled titles during the study period were duplicated on that campus.

With none of the libraries giving the full information required by the study, a number of additional sources were used to complete each record. These included the OCLC database, Ulrich's International Periodicals Directory, Faxon's Librarian's Guide to Serials, the University of Illinois' online catalog, Illinet Online, and MELVYL, the online catalog of the University of California Libraries.

In addition, the study sought information from the CDOs at the twelve CIC libraries concerning their cancellation decisions. Each was sent a survey asking him or her to rank the factors considered in making cancellations; his or her opinions on other related topics were solicited.

\section{RESULTS}

Because the completed database contains nine fields for each cancelled serial title, and each field can be indexed to act as a "searchable field," the capabilities for data analysis were enormous. Some basic cross-tabulations were made to create a profile of cancelled titles, explore cancellation patterns, and test the hypotheses.

\section{Total Cancellations by School}

Total cancellations numbered 6,503 titles. Unique titles numbered 6,222 , with 281 titles ( 4 percent) cancelled at two or more schools. Surprisingly, no overlap occurred among all five schools in this study, and only one title was can- celled by four schools (Who's Who in America, an obvious cancellation of a duplicate title).

The University of Illinois at UrbanaChampaign had the most cancellations $(2,279)$, but also reported the largest total serials holdings. It was followed in total number of cancellations by Michigan State University $(1,558)$, University of Iowa $(1,336)$, University of Wisconsin (872), and Ohio State University (458).

\section{Serial Cancellation Prices}

Serial cancellation prices for the five schools during the study period totaled $\$ 690,225.64$ (see table 3). Serial prices are based on reported subscription price, and do not account for processing, binding, or storage costs associated with the titles. The average cost of a cancelled title was $\$ 121.71$. This average cost is slightly lower than the average cost of $\$ 127.79$ for academic libraries during fiscal years 1987-88 through 1989-90 that was figured by Peter K. Young. ${ }^{8}$ Table 4 compares Young's data on serial holdings in academic libraries to this study's data on cancelled serial titles, sorted by cost (less than $\$ 100$, between $\$ 100$ and $\$ 200$, and over $\$ 200$ ). Most categories consistently correlate the percent of holdings and cancellations, with slightly fewer titles cancelled on average in each category. However, in looking at expenditures, titles that cost over $\$ 200$ show a higher than average rate of cancellation compared to holdings, confirming the hypothesis that the more expensive titles are being singled out for cancellation.

Table 3 and figure 1 show relative serial cancellation costs. The most dramatic statistic shows that titles costing over $\$ 200$ accounted for only 12 percent of titles overall, but 64 percent of the total cost. At the opposite end of the spectrum, the less expensive titles (less than $\$ 100$ per year) account for only 22 percent of the cost but 70 percent of the titles cancelled.

\section{Language and Place of Publication}

It was hypothesized that more than 50 percent of cancellations would be titles published outside the United States. 


\section{TABLE 3}

NUMBER OF TITLES AND COST OF TITLES

FOR SERIAL CANCELLATIONS 1987-88-1989-90 AT THE FIVE SAMPLE LIBRARIES

\begin{tabular}{|c|c|c|c|c|c|c|}
\hline & $\begin{array}{c}\text { Greater than } \\
\$ 200\end{array}$ & $\begin{array}{l}\text { Between } \\
\$ 100-\$ 200\end{array}$ & $\begin{array}{l}\text { Less than } \\
\$ 100 .\end{array}$ & Gifts $\$ 0.00$ & $\begin{array}{c}\text { Without } \\
\text { Prices }\end{array}$ & Total \\
\hline Illinois & $\begin{array}{c}198 \\
\$ 104,951.44\end{array}$ & $\begin{array}{c}220 \\
\$ 29,297.13\end{array}$ & $\begin{array}{c}1,806 \\
\$ 52,709.54\end{array}$ & $\begin{array}{l}55 \\
\$ 0\end{array}$ & 0 & $\begin{array}{c}2,279 \\
\$ 186,958.11\end{array}$ \\
\hline Iowa & $\begin{array}{c}181 \\
\$ 98,066.44\end{array}$ & $\begin{array}{c}208 \\
\$ 28,830.13\end{array}$ & $\begin{array}{c}836 \\
\$ 38,362.87\end{array}$ & $\begin{array}{r}3 \\
\text { s0 }\end{array}$ & 108 & $\begin{array}{c}1,336 \\
\$ 165,259.44\end{array}$ \\
\hline $\begin{array}{l}\text { Michigan } \\
\text { State }\end{array}$ & $\begin{array}{c}111 \\
\$ 68,227.46\end{array}$ & $\begin{array}{c}126 \\
\$ 17,346.28\end{array}$ & $\begin{array}{c}733 \\
\$ 27,577.72\end{array}$ & $\begin{array}{r}317 \\
\$ 0\end{array}$ & 271 & $\begin{array}{c}1,558 \\
\$ 113,151.46\end{array}$ \\
\hline Ohio State & $\begin{array}{c}56 \\
\$ 46,851.45\end{array}$ & $\begin{array}{c}66 \\
\$ 8,883.46\end{array}$ & $\begin{array}{c}312 \\
\$ 13,209.14\end{array}$ & $\begin{array}{r}0 \\
\$ 0\end{array}$ & 24 & $\begin{array}{c}458 \\
\$ 68,944.05\end{array}$ \\
\hline $\begin{array}{l}\text { University } \\
\text { of Wisconsin } \\
\text { Madison }\end{array}$ & $\begin{array}{c}155 \\
\$ 119,434.36\end{array}$ & $\begin{array}{c}103 \\
\$ 14,334.41\end{array}$ & $\begin{array}{c}560 \\
\$ 22,143.81\end{array}$ & $\begin{array}{r}0 \\
\$ 0\end{array}$ & 54 & $\begin{array}{c}872 \\
\$ 155,912.58\end{array}$ \\
\hline Total & $\begin{array}{c}701(12 \%)^{*} \\
\$ 437,531.15 \\
(64 \%)\end{array}$ & $\begin{array}{c}723(12 \%)^{*} \\
\$ 98,691.41 \\
(14 \%)\end{array}$ & $\begin{array}{c}4,247(70 \%)^{*} \\
\$ 154,003.08 \\
(22 \%)\end{array}$ & $\begin{array}{l}375 \\
(6 \%)\end{array}$ & 457 & $\begin{array}{c}6,503 \\
\$ 690,225.64\end{array}$ \\
\hline
\end{tabular}

6,046 titles ( $93 \%$ of database) have prices or gift/exchange status.

457 titles ( $7 \%$ of database) could not be assigned a price.

Average cost of a title $=\$ 121.71$ (based on titles with prices).

* Percent of titles with prices $(5,671)$.

\section{TABLE 4}

COMPARISONS OF AVERAGES FOR TOTAL NUMBER

OF SUBSCRIPTIONS AND TOTAL EXPENDITURES FOR SERIALS SORTED BY COST, 1987-88-1989-90, HELD BY ACADEMIC LIBRARIES (FROM YOUNG, 1990) AND CANCELLED BY THE FIVE SAMPLE LIBRARIES

\begin{tabular}{lcc}
\hline & \multicolumn{2}{c}{ Percent of Total Subscriptions } \\
\cline { 2 - 3 } & $\begin{array}{c}\text { Academic Library Holdings } \\
\text { from Young (1990) }\end{array}$ & $\begin{array}{c}\text { Five Sample ARL Libraries Serial } \\
\text { Cancellations* }\end{array}$ \\
\hline Less than $\$ 100$ & $75 \%$ & $70 \%$ \\
Between $\$ 100-\$ 200$ & 13 & 12 \\
Greater than $\$ 200$ & 13 & 12 \\
& Percent of Total Expenditures for Serials \\
Less than $\$ 100$ & $26 \%$ & $22 \%$ \\
Between $\$ 100-\$ 200$ & 15 & 14 \\
Greater than $\$ 200$ & 59 & 64 \\
\hline
\end{tabular}

Percentages rounded to the closest whole number.

* Six percent of cancelled serials were gift/exchange titles.

English-language domestic titles often form many collections' core, which is a strong reason for maintaining these titles. In fact, domestic titles accounted for less than one-half $(2,956$, or 47 per- cent) of the serial cancellations. These were followed by publications from Great Britain (513, or 9 percent), West Germany (488, or 9 percent), and the Netherlands (215, or 4 percent). Place of 


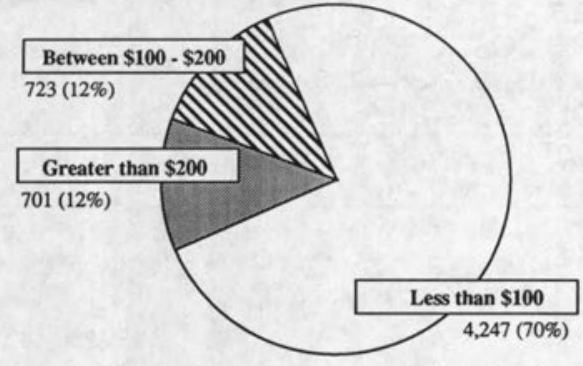

Number of Titles Cancelled by Price

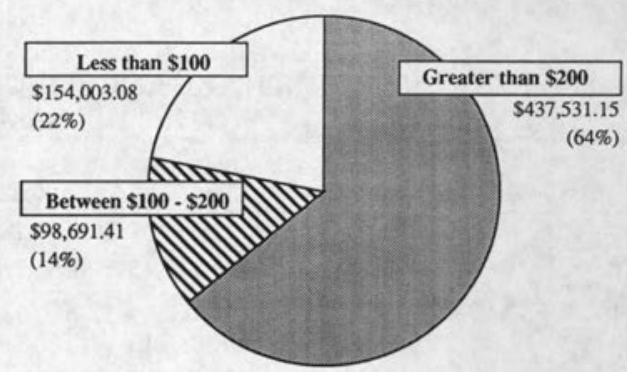

Cost of Titles Cancelled by Price

FIGURE 1

Number of titles and cost of titles for serial cancellations, 1987-88 through 1989-90.

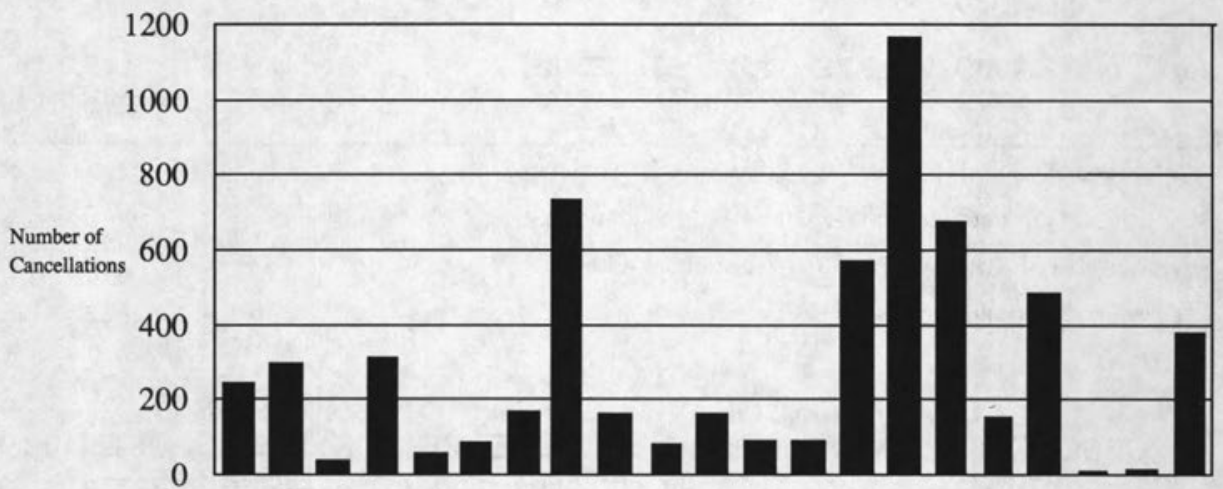
A B C
D $F$ G H
K L M N

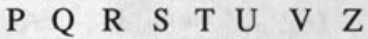
LC Classifications

FIGURE 2

LC classifications of 6,247 cancelled serial titles for the five sample libraries, 1987-88 through 1989-90

publication was assigned to 5,566 ( 89 percent) of the titles in the database.

English was the language of publication of most of the cancelled titles $(4,153$, or 74 percent). Non-English titles totaled 1,431 , or 26 percent. The high percentage of English-language serial cancellations may reflect the fact that most of the United States's library collections are predominantly in English. ${ }^{9}$ Language was assigned to 5,584 ( 89 percent) of the titles in the database.

\section{Library of Congress Subject Analysis}

Library of Congress (LC) call numbers were assigned to those cancellation rec- ords for which no call numbers were reported and to Illinois' cancellation lists, which were reported in Dewey classification. Ninety-six percent, or 6,247 titles, were assigned call numbers. Figure 2 shows a bar chart for all five libraries sorted into broad LC classifications. Science call numbers $Q$ (science), R (medicine), S (agriculture), and $\mathrm{T}$ (technology) represent approximately 40 percent of cancelled titles assigned call numbers. $Q$ classification by itself is the largest subject cancellation area, with 1,161 titles or 19 percent of cancellations with call numbers. $Q$ was also the call number class with the largest overlap, accounting for 31 percent of the 
overlapping cancelled titles. It was followed by $\mathrm{R}$ ( 21 percent), $\mathrm{H}$ (social sciences, 8 percent), and $\mathrm{T}$ ( 6 percent).

Snapshot profiles of call number analysis for the five individual libraries varied from one another according to the circumstances surrounding each library's cancellation requirements. Cancellations at Ohio State University, for example, were of duplicates only. Their cancellation profile reflects a heavier concentration of $A$ and $Z$ (primarily reference material), and $\mathrm{H}$ (social sciences) than do the other schools. The subject cancellation profile of the University of Illinois at Urbana-Champaign shows a relatively high number of $\mathrm{P}$ (language and literature) cancellations. This profile reflects the strength of the collection in this area as well as an attempt to cut subject funds "across the board." Since humanities/social science serials typically cost less than science journals, more humanities titles were cancelled to meet subject-fund deficits.

\section{CDO DECISION MAKING}

Collection development officers from the twelve CIC schools were surveyed about rationales for serial cancellation decisions. Seventy percent of the respondents ranked "use of the title" as the top factor to be considered when making cancellation decisions. The second-most cited factor was "title is a duplicate," followed by the journal's cost. While Ohio State University reported that all of its cancellations during the study were of duplicates, most libraries reported that cancellation of duplicates was no longer an option. Herbert White reported in his 1980 survey of serial cancellations that 82 percent of cancellations were of titles unique to each library. In his previous survey, White found duplicates the most likely to be cancelled. He concluded, "... it seems more likely that at least some of the unique subscriptions are being cancelled because the duplicates-at least the most obvious duplicates-are already gone." 10 With the issue of duplicates mostly a moot point because many academic libraries shed their duplicate serials in the early 1980s, this survey of CDOs concludes that cost and observed use are the two most important factors considered when journals are cancelled. Margaret Hawthorn's 1990 survey of 223 United States and Canadian academic libraries confirms the importance of journal cost to selectors when evaluating serials for cancellation. The cost of a journal was reported as the most important reason to select a title for cancellation. ${ }^{11}$

$\mathrm{CDO}$ opinions were also sought on the depth of serial "retrenchment." Ten of the twelve CDOs said they expect to cancel serials in fiscal year 1993, and ten also see serial cancellations as "an established trend" in academic libraries.

\section{CONCLUSIONS}

Two hypotheses were proposed. The first posited that at least 30 percent of cancellations would be of the same title at two or more of the five libraries. Because only 4 percent of the cancelled titles were cancelled by two or more libraries, this hypothesis was rejected. The second hypothesis stated that a composite of the typical cancelled serial would most likely be a non-English science title, published outside the United States and costing at least $\$ 200 \mathrm{a}$ year. In fact, about 82 percent of the cancelled serials cost less than $\$ 200$. In addition, almost half were published in the U.S., and some 74 percent were in English. For these factors, at least, the second hypothesis also was not supported. However, science titles in the Q, R, S, and $T$ classifications accounted for approximately 40 percent of the cancellations, clearly representing a significant portion of the cancellations. This part of the second hypothesis, then, is supported.

While the majority of titles cost less than $\$ 200$, it is important to reiterate that, as shown in table 4, there is an obvious bias toward the cancellation of highpriced serials. This table shows that, at least in our recent past, cancellation decisions are being made on the basis of cost: higher-priced titles are being targeted for cancellation. This is borne out by the responses from the collection development officers, and by Hawthorn's 1990 
survey. It may also suggest that science titles, which generally cost the most, have been protected in the past and are now vulnerable.

Upon reflection, it was not surprising that most cancellations were of Englishlanguage titles, given that English is the publication language of choice not only for much of North America but also for many titles published in Europe and elsewhere. Also it is likely that many of the foreign titles received in large academic libraries arrive through gift or exchange, and therefore cancellation would have minimal budgetary impact. Additionally, foreign titles in many humanities and social science disciplines in particular are lower in price than are Englishlanguage titles, and cost savings from cancellation would not be as great.

Ten of the twelve CDOs said they expect to cancel serials in fiscal year 1993, and ten also see serial cancellation as an "established trend" in academic libraries.

As suggested earlier, science and technology serials, which have suffered in sheer number of cancellations, may have been protected in preceding years and are just now catching up to cancellations in the social sciences and humanities. One of the libraries in the study group reported that science serials accounted for about 50 percent of their overall materials budget and some 70 percent of their serials budget. Science cancellations in this library were a planned strategy to achieve a different balance in the collection. Cancellations in these areas can generate a substantial amount of money as well, and as cuts into materials budgets deepen, this becomes more critical. Science collections tend to purchase serials more heavily than do the other disciplines. Because of these tendencies, the result upon the science collection of any one library can be quite devastating.

The sciences also serve disciplines which historically have required the building of departmental libraries. In turn, these libraries have generated a substantial number of duplicates to serve the departmental libraries which now are required to trim their resources. This study was not able to collect reliable data on the cancellation of duplicates, so it is not possible here to pursue this line of investigation.

Coupled with all this are data from this study that show that, when cancellation overlap occurs, it is likely to occur in these same science areas. Overall, this study indicates that libraries may becancelling unique titles in favor of maintaining high-use, core titles. Science collections, representing a significant portion of the cancellations and a large portion of the cancellation overlaps, would now seem to be in a position where they have cancelled their unique titles and are down to cancelling their core titles. The difficulties found in one library are then spread to other libraries. This means that fewer and fewer libraries will be able to provide access to particular titles, and it suggests that this constriction is already starting with our science collections. This is a supposition that will be tested in future research.

Why were so few cancellations duplicated from library to library? An analysis of this question suggests some troubling findings. Existing overlap studies, almost entirely devoted to the study of monographs, suggest that research libraries have a high percentage of unique monograph titles. However, the universe of serial publishing is much smaller; while research libraries undoubtedly hold unique serial titles that reflect the focus of each university, serial overlap between libraries of similar age, size, and type is estimated at between 24 and 68 percent, as noted earlier. Studies of serial overlap include publications by Christine Johnston, Donald D. Thomp-son, and Richard M. Dougherty, as well as by Stroyan and Hooper. Johnston reports overlap in chemistry journals between two academic libraries to range from 30 percent of total serials to 39 percent of currently received serials. Thompson and Dougherty measured serial overlap at the northern campuses of the University of California in 1974. An overall serials overlap rate of 37 percent 
was found among six libraries, and overlap rates between two libraries ranged from 5 percent (comparing small to large collections) to 87 percent (comparing large to small collections). Stroyan found serial overlap in hospital libraries to range from 24 to 36 percent, again varying with the size of the library. Hooper found an average serial overlap of 58 percent between two South African university libraries. Overlap peaked in specific subject areas of medicine and science, both at 68 percent. ${ }^{12}$

These statistics show that serials are more likely than monographs to overlap between libraries. If similar libraries are not cancelling within the overlap universe, then they must be cancelling titles from their unique universe. The Matthew Effect, a concept developed by Robert $\mathrm{K}$. Merton to describe the recognition that accrues to prolific scientists, can be applied to library serial cancellations and helps define the phenomenon of the development of similar collections of high-use and frequently cited serial titles. ${ }^{13}$ Based on the Gospel of St. Matthew ("For unto every one that hath shall be given, and he shall have abundance: but from him that hath not shall be taken away even that which he hath"), the Matthew Effect, in this context, suggests that high-use items will be used and demanded by researchers and maintained by libraries, while low-use titles unique to each collection are susceptible to cancellation.

These conclusions are presented with some caveats that must be kept in mind. This study looked at cancellations, not holdings or serial additions to collections. It also covered an isolated period and cannot describe activity or motivations for cancellations made earlier, or the effects these cancellations have had during the study period. Finally, serial overlap studies simply are not specific, detailed, or numerous enough for absolute reliance on the data they have produced. Further studies will help validate current research.

\section{FUTURE RESEARCH}

The results of this study point to the need to conduct research on the obverse issue, that of analyzing the serial collections that remain after the cancellations. A detailed look at chemistry serial collections is planned for future research. This second study will focus on serial holdings compared to serial cancellations, if cancellations were duplicates within that library or at other libraries in the study, and how important the cancelled titles are to chemistry research.

Another important issue that should be explored concerns the impact of serial cancellations on a collection. Are cancelled titles actually important to the collection; can they be deleted without affecting the success of the user in obtaining needed information; or, are they high-use titles for which there is no substitute? Among libraries with cooperative agreements, does the cancellation affect other libraries and other users? In many ways, use studies are a pivotal issue in the research of cancellations.

The lack of complete data consistent among libraries is a major hindrance to future research efforts. Data on serials cancellations are as important as data on serial acquisitions. Complete machinereadable data would be beneficial to future research in this area.

\section{SUMMARY}

This research provides a profile for the at-risk serial. The profile-a high-cost English-language title in a science subject area-suggests that our serial collections are diminishing in parallel ways. In many ways, it would be more heartening to discover that there are few characteristics that define the cancelled serial. If cancellations came from a variety of countries in many languages from all disciplines, there would be less reason for concern about the vitality of our collections. That there seems to be emerging a recognizable profile of the cancelled serial title is cause for concern.

The disturbing conclusion is this: if libraries are not cancelling the same title, then it may be presumed that they are cancelling titles unique to the group. By this act, the diversity that has been the hallmark of our research institutions is disappearing. This situation calls for a 
renewed interest in cooperative collection development that addresses the issues of cancellations. It has become increasingly clear to libraries that inter- dependence defines the future. To the list of cooperative ventures, libraries should now add discussions of what they can and cannot afford to buy.

\section{REFERENCES AND NOTES}

1. Ann Okerson, "Of Making Many Books There Is No End: Contractor Report for the Association of Research Libraries (ARL)," in Report of the ARL Serials Prices Project (Washington, D.C.: Association of Research Libraries, 1989).

2. Kenneth E. Marks and others, "Longitudinal Study of Scientific Journal Prices in a Research Library," College \& Research Libraries 52 (Mar. 1991): 125-38.

3. Ann Okerson and Kendon Stubbs, "The Library 'Doomsday Machine,'" Publisher's Weekly 237 (Feb. 8, 1991): 36-37.

4. Susan E. Stroyan, "Collection Overlap of Eight Hospital Libraries in a Health Sciences Consortium," Ph.D. diss., Univ. of Illinois at Urbana-Champaign, 1986.

5. A.S.C. Hooper, "Overlapping Journal Subscriptions as a Factor in University Library Co-operation," South African Journal of Library and Information Science 58, no.1 (Mar. 1990): 25-32.

6. The CIC institutions include Ohio State University, Indiana University, University of Iowa, Purdue University, Michigan State University, University of Michigan, University of Illinois at Urbana-Champaign, University of Minnesota, Northwestern University, University of Wisconsin-Madison, Pennsylvania State University, and the University of Chicago.

7. Association of Research Libraries. ARL Statistics 1989-90 (Washington, D.C.: Association of Research Libraries, 1991), 7-8.

8. Peter R. Young, "Periodical Prices 1988-1990," Serials Librarian 18, no. 3/4 (1990): 1-21.

9. Data on holdings by language are not available, but supporting evidence of this statement can be found in, among other places, Rose Mary Magrill and John Corbin, Acquisitions Management and Collection Development in Libraries 2d ed. (Chicago: ALA, 1989), 132. The authors note the difficulty in acquiring foreign-language material and the number of titles that are produced in English worldwide.

10. Herbert S. White, "Factors in the Decision by Individuals and Libraries to Place or Cancel Subscriptions to Scholarly and Research Journals," Library Quarterly 50 (July 1980): 304.

11. Margaret Hawthorn, "Serials Selection and Deselection: A Survey of North American Academic Libraries," Serials Librarian 21, no. 1 (1991): 38.

12. Christine Johnston, "Automated Collection Assessment: CASSI as a Tool," Technical Services Quarterly 8 (1990): 43-54; Donald D. Thompson and Richard M. Dougherty, Preliminary Summary Report on the Feasibility of Expanded Library Cooperation among the Northern Campuses of the University of California: A Study of Periodicals Overlap and Patterns of Use (Berkeley, Calif.: Univ. of California, 1974) 1; Stroyan, "Collection Overlap," 55; Hooper, "Overlapping Journal Subscriptions," 25.

13. Robert K. Merton, "The Matthew Effect in Science," Science 159 (Jan. 5, 1968): 56-63. This concept was used to describe journal collections by Stephen J. Bensman in his article "Journal Collection Management as a Cumulative Advantage Process," College \& Research Libraries 46 (Jan. 1985): 18. 